\title{
RÉGIMEN CONSTITUCIONAL DE LOS TRATADOS DE DERECHOS HUMANOS EN EL DERECHO COMPARADO LATINOAMERICANO*
}

\author{
Karen G. Añaños Bedriñana"
}

Fecha de recibido: 5 de agosto de 2014

Fecha de aprobado: 30 de septiembre de 2014

Artículo de reflexión

Forma de citación: Añaños, K. (2015). Régimen constitucional de los tratados de derechos humanos en el derecho comparado latinoamericano. Revista Prolegómenos. Derechos y Valores, $18,35,135-151$.

\section{Resumen}

El presente artículo aborda el estudio de la problemática constitucional actual, sobre la primacía de los tratados de derechos humanos en el derecho interno de los Estados latinoamericanos. Se analiza, comparativamente, una serie de cláusulas sobre el carácter (supraconstitucional, constitucional, supralegal o legal) que conceden las constituciones a los tratados, frente a su propia legislación, cuando se incorporan en su derecho interno. Por último, se pretende que los tratados de derechos humanos se consideren un instrumento conceptual y operacional de todas las personas que están inmersas en este proceso, dentro de la función pública estatal. Y, en este contexto, se pueda superar la inexistencia, o la ambigüedad de las cláusulas constitucionales, que puede ocasionar conflictos en la aplicación de un tratado en el derecho interno.

\section{Palabras clave:}

Constitución, derecho interno, Latinoamérica, primacía, tratados de derechos humanos.

\footnotetext{
* Artículo de investigación elaborado en el marco de la tesis doctoral "El Sistema Interamericano de Derechos Humanos y la aplicación de tratados sobre derechos humanos en el derecho interno peruano", Departamento de Derecho Constitucional de la Universidad de Granada, España (2014).

* Doctoranda del Departamento de Derecho Constitucional de la Universidad de Granada y colaboradora de la cátedra Jean Monnet ad persónam de Derecho Constitucional Europeo y Globalización de la Comisión Europea. Con diversos estudios de posgrado en España, entre otros: magíster en De $\neg$ recho Constitucional Europeo, Universidad de Granada y magíster interuniversitario en Diplomacia y Relaciones Internacionales, Escuela Diplomática de Madrid. Abogada internacional. Correo electrónico: karengab@ugr.es
} 


\title{
CONSTITUTIONAL LEGAL SYSTEM OF HUMAN RIGHTS TREATIES IN LATIN AMERICAN COMPARATIVE LAW
}

\begin{abstract}
This article analyzes the current constitutional issues on the primacy of human rights treaties over domestic law in Latin American States. A series of clauses on (supra-constitutional, constitutional, supralegal or legal) character granted by constitutions to treaties, against its own legislation and when incorporated into domestic law, is comparatively analyzed. Finally, it is intended that human rights treaties are considered a conceptual and operational tool for all those who are engaged in this process within the state public service. And, in this context, that the lack or ambiguity of constitutional clauses, which can cause conflicts in the implementation of a treaty in domestic law, can be overcome.
\end{abstract}

\section{Keywords:}

Constitution, domestic law, Latin America, primacy, human rights treaties.

\section{REGIME CONSTITUCIONAL DOS TRATADOS DE DIREITOS HUMANOS INO ÂMBITO DO DIREITO COMPARADO LATINO-AMERICANO}

\section{Resumo}

O presente artigo foca o estudo da problemática constitucional atual no que diz respeito à primazia dos tratados de direitos humanos no direito interno dos Estados latino-americanos. Analisa-se, de maneira comparada, uma série de cláusulas sobre o caráter - supranacional, constitucional, supralegal ou legal - que nas constituições confere-se aos tratados, em relação com a legislação doméstica, ao incorporá-los no direito interno. Por fim, visa-se que os tratados de direitos humanos se tornem instrumentos conceituais e operacionais de todas as pessoas envolvidas nesse processo, no âmbito da função pública estatal. E nesse contexto, pretendese superar a inexistência ou ambiguidade das cláusulas constitucionais que possam dar azo a conflitos quando da aplicação de um tratado no direito interno.

\section{Palavras-chave:}

Constituição, direito interno, Latino-América, primazia, tratados de direitos humanos.

\section{INTRODUCCIÓN}

El presente artículo tiene como objeto efectuar un análisis comparativo de cláusulas normativas de las diferentes constituciones latinoamericanas (Argentina, Bolivia, Brasil, Colombia, Costa Rica, Ecuador, El Salvador, Guatemala, Honduras, México, Nicaragua, Paraguay, Perú y Uruguay).

En ese sentido, el documento se divide en los siguientes apartados. Primero, se estudia, de manera sintética, el nuevo contexto global en el que se materializa el derecho internacional de los derechos humanos, con sus luces y sombras, en cuanto a la incorporación de los tratados de derechos humanos. Segundo, se analiza, comparativamente, las cláusulas constitucionales, de acuerdo con el carácter (supraconstitucional, constitucional, supralegal o legal) que le otorga la Constitución de los diferentes Estados a los tratados de derechos humanos.

A fin de alcanzar nuestro propósito, se utilizó el método bibliográfico o documental, que consiste 
en recopilar, sistematizar y analizar la información encontrada en libros, artículos, diversas constituciones latinoamericanas y en medios telemáticos. Además, se contó con el apoyo de herramientas metodológicas de tipo histórico, descriptivo y comparativo.

Precisamente, el derecho comparado facilita el examen de la situación jurídica real en las constituciones latinoamericanas, respecto a los tratados de derechos humanos. En este orden de ideas, consideramos necesario señalar algunos hitos históricos que marcaron, genéricamente, un antes y un después en la evolución relativamente reciente de esta temática en los diferentes Estados.

Así, después de la Segunda Guerra Mundial, se toman medidas urgentes trascendentales, que tienen como pilar el reconocimiento y la defensa de los derechos humanos.

Hay que destacar que el desarrollo jurídico más importante del siglo XX, y de lo que va del XXI, se ha registrado, de seguro, en el área del derecho internacional de los derechos humanos, que ha logrado tener una gran relevancia en los sistemas jurídicos nacionales de los Estados latinoamericanos (Albanese, 2008; García-Sayán, 2003a).

Una construcción que empezó en 1948, y cuyo devenir no ha sido nada fácil, ni tampoco unidireccional. En esta línea, para la humanidad y el continente americano, se identifican dos hechos significativos, que sellaron la evolución jurídica de los derechos constitucionales: la proclamación de la Declaración Universal de Derechos Humanos (DUDH) de la Organización de las Naciones Unidas y la Declaración Americana de Derechos Humanos (DADH). Esta última antecedió a la Universal, convirtiendo a este territorio en una zona pionera en el reconocimiento de derechos humanos.

En el hemisferio americano, el sistema regional de derechos humanos, conocido como Sistema Interamericano de Derechos Humanos, es el que vela por la promoción y protección de los derechos humanos de sus ciudadanos. Este y el
Sistema Europeo de Derechos Humanos, constituyen los principales continentes defensores de la democracia, el respeto y el reconocimiento a la dignidad humana.

En el Sistema Interamericano, la Organización de Estados Americanos (OEA) como entidad regional intergubernamental y no supranacional, es el foro gubernamental político, jurídico y social más sobresaliente, que integra a la mayoría de los Estados americanos, en un total de treinta y cinco; en tanto que la Convención Americana sobre Derechos Humanos (CADH), es su principal tratado internacional de derechos humanos. También hay que nombrar la carta constitutiva de la OEA y la DADH, que configuran el fundamento jurídico de sus actuaciones.

Los derechos humanos en este continente tienen unas particularidades que no se presentan en otras regiones. Así, gran parte de los países que conforman la OEA, se caracterizan por una historia plagada de caudillismos, golpes de Estado, inestabilidades políticas, con una ausencia de estructuras institucionales sólidas y eficaces (Gros, 1988); y por una situación de pobreza (Durán, 1993). A pesar de todos estos inconvenientes, la lucha de los pueblos, como base, ayudó a recuperar la posibilidad de contar con regímenes democráticos (García-Sayán, 2003b).

En estos últimos tiempos-influenciados por el proceso de globalización-, la evolución social, los aportes teóricos, la consolidación de los derechos y la propia dinámica del tiempo han traído consigo cambios en todos los niveles, que han afectado, en mayor o menor medida, a prácticamente todas las partes del mundo. Este nuevo entorno ha favorecido a los sistemas de protección internacional universal o regional de derechos humanos.

Siguiendo esta lógica, en los ordenamientos nacionales, el catálogo de los derechos humanos nunca ha sido estático, por cuanto se ha ido definiendo y consagrando, de acuerdo con el "desarrollo histórico de la sociedad, de la organización del Estado y del propio progreso de los regímenes 
políticos. Ello explica la pauta evolutiva de los contenidos de los derechos humanos" (GarcíaSayán, 2003a, p. 93).

A partir de mediados de la década de los setenta, diferentes constituciones latinoamericanas reflejaron la incorporación de instrumentos internacionales de derechos humanos en el derecho interno. Sin embargo, no es una situación exclusiva del constitucionalismo latinoamericano, ya que hay diversas constituciones, en concreto, en Asia y África, y de manera más reciente, en Europa del Este, que mencionan expresamente a las normas del derecho internacional de los derechos humanos, en especial a la DUDH (Dulitzky, 1997).

En este contexto, importantes mecanismos internacionales y de protección, se han puesto en funcionamiento, tanto en el escenario nacional como en el global. Aunque en palabras de Diego García-Sayán, "este impulso jurídico e institucional, sin embargo, no ha tenido un desarrollo paralelo unívoco y lineal, en los procesos jurídicos e institucionales, al interior de los países" (2010, p. 13).

Ahora bien, los tribunales internacionales van a desempeñar un papel trascendental en la consecución del mismo. Prueba de ello, en el ámbito global son los casos resueltos por los tribunales en Canadá, Alemania, India, Nueva Zelanda, Gran Bretaña e, incluso, Estados Unidos; y, más recientemente, en el continente americano, se pueden nombrar los casos de Argentina, Chile, Colombia, Guatemala y Perú (Rodríguez, 2009).

En definitiva, en las constituciones latinoamericanas se detecta una tendencia a recurrir a los tratados internacionales sobre derechos humanos, en especial a la $\mathrm{CADH}$, como también a decisiones jurisprudenciales emitidas por la Corte Interamericana de Derechos Humanos, con el fin de resolver casos nacionales.

\section{A. Las luces y sombras de la incorporación de los tratados de derechos humanos}

Si bien es cierto que la "universalización" de los derechos humanos, de la que nos habla Norberto
Bobbio (1982), se constituye en una etapa esencial para el afianzamiento de la protección de los derechos humanos, en la actualidad, el desafío es la "nacionalización" de los derechos humanos universales, impulsada por la Corte Interamericana de Derechos Humanos.

En América Latina, este proceso se erige como uno de los factores que ha determinado una protección efectiva de los derechos humanos (Almirón, 2009; García-Sayán, 2010).

Conforme señala García-Sayán (2003a), hay que hacer mención al avance, por parte de los tribunales nacionales, en comprender que el derecho internacional de los derechos humanos es la pieza esencial del Sistema Interamericano.

Por ello, una de las estrategias más esperanzadoras para lograr la vigencia de los derechos humanos, en un país en concreto, consiste en proyectar, en ese Estado, reglas de derecho internacional declarativas de los derechos humanos.

De acuerdo con el profesor Néstor Sagüés (2005), su materialización tiene ciertas ventajas: primero, significa que, en el Estado en cuestión, ciertos derechos humanos deben regir no solo por voluntad del Estado, sino también por la voluntad de otros Estados e, incluso, de una organización supranacional. Segundo, advierte que en la vigencia de los derechos humanos, se encuentran comprometidos el bien común nacional, pero, así mismo, el bien común internacional; y tercero, el incumplimiento de un tratado internacional de derechos humanos, por parte de un Estado, acarrea responsabilidad internacional.

En ese sentido, la mayoría de constituciones latinoamericanas antiguas, no hace alusión a la cuestión de los derechos humanos y guarda silencio, respecto a la incorporación de tratados en el ordenamiento interno, aunque algunas han sido reformadas. Las que sí citan este concepto, son cartas políticas relativamente nuevas (Álvarez, 2001; Dulitzky, 1997).

Refiere Elodia Almirón (2009) que en el marco de las recientes reformas constitucionales, el tema de la primacía de los tratados internacionales 
ha generado cambios dentro de los regímenes normativos nacionales. Este proceso no ha sido igual en todos los Estados, sino que cada uno lo ha interiorizado en su ordenamiento nacional, conforme a su realidad jurídica.

En cuanto a este tema, surgen cuestiones a resolver. En primer lugar, sobre los medios de incorporación, el cómo y el cuándo el derecho humano supranacional rige en la esfera local nacional; en segundo lugar, tratar sobre la primacía del tratado internacional y de los derechos que contiene, respecto al resto de las normas nacionales (en particular, la Constitución y las leyes ordinarias); y en tercer lugar, acerca de la operatividad (inmediata o retardada), del derecho humano, de fuente internacional, una vez incorporado al derecho local (Sagüés, 2005).

Planteada esta situación, cabe decir que son distintos los caminos de integrar los tratados de derechos humanos en el derecho nacional. Y recordar que en cada Estado este tipo de tratados de derechos humanos cuenta con diferente cotización frente a las normas locales; y es precisamente este punto el que desarrollaremos en los siguientes párrafos.

Por último, mencionar que el funcionamiento de cada uno de los derechos humanos no goza siempre de la misma ejecutividad. En ese sentido, existen variables bien distintas, con efectos jurídicos, a su vez, diferentes.

En consecuencia, señala el profesor Sagüés (2005), que la incorporación al derecho interno de los derechos humanos, expresados en una convención o tratado internacional, le concede a esos "derechos humanos un fundamento 'reforzado' de aplicación de tipo normativo, axiológico y hasta táctico" (Sagüés, 2005, p. 95).

\section{B. El régimen constitucional de los tratados internacionales de derechos humanos}

Partimos de la idea de que los tratados de derechos humanos forman parte del "bloque de constitucionalidad" o "bloque constitucional" de los sistemas jurídicos de los Estados latinoamericanos, siendo los tribunales nacionales denominados en algunas naciones como Tribunal Constitucional o Corte Constitucional, los principales responsables de llevar adelante esta tarea.

No obstante, en el ámbito supranacional, mediante sus sentencias, la Corte Interamericana deberá impulsar grandes avances dentro de los ordenamientos internos de los Estados; primero, como pautas de interpretación y, posteriormente, cuando sus fallos se consideren de obligatorio cumplimiento, por los tribunales nacionales. Por ello, la jurisprudencia de la Corte sirve de parámetro a los tribunales nacionales que, cada vez más, se inspiran en los criterios de esta institución para resolver sus casos internos (véase García-Sayán, 2003a, 2010).

La exigente preselección de la Comisión Interamericana, en casos individuales, hace que las sentencias emitidas por la Corte Interamericana sientan precedentes, e influyan en el tratamiento que otorgan los ordenamientos internos a una gran cantidad de casos asimilables o, incluso, a áreas temáticas completas.

Entre los casos más destacados se citan: "La última tentación de Cristo" vs. Chile; Castillo Petruzzi vs. Perú; Paniagua Morales "Panel Blanca" vs. Guatemala; "Niños de la Calle" vs. Guatemala; Bámaca Velásquez vs. Guatemala; Bulacio vs. Argentina; Claude Reyes vs. Chile; Almonacid Arellano vs. Chile; y más recientemente, los casos "Campo Algodonero" vs. México y Atala Riffo vs. Chile.

El caso paradigmático por excelencia es el de Barrios Altos vs. Perú, en el que un tribunal internacional constató que una ley nacional carecía de validez jurídica, por violar el derecho internacional. Por tanto, la Corte Interamericana condenó al Estado peruano por la violación de los derechos contenidos en la CADH, revocando las leyes de amnistía ${ }^{1}$. En ese sentido, Perú cumplió

\footnotetext{
1 Versa sobre la ejecución de quince personas en el centro de Lima, en el lugar llamado Barrios Altos, por parte de agentes del Estado conocidos como grupo paramilitar "Colina". Cfr. Eguiguren (2004), García (2002),GarcíaSayán(2003, 2005, 2008) y Salado(2004).
} 
con el veredicto y anuló las leyes de amnistía 26479 y 26942 (véase Pontificia Universidad Católica del Perú, 2003).

El presente caso, es una muestra muy clara, de cómo la Corte Interamericana ha venido construyendo progresivamente la prevalencia de la $\mathrm{CADH}$ sobre las normas nacionales, frente a graves violaciones de los derechos humanos en contra de los latinoamericanos (véase Corte Interamericana de Derechos Humanos: casos Castillo Páez vs. Perú, de 27 de noviembre de 1998, párr. 105, y Barrios Altos vs. Perú, sentencia de interpretación de fondo, de 3 de septiembre de 2001).

Siguiendo esta misma línea, se encuadra el caso Suárez Rosero vs. Ecuador, donde la Corte Interamericana estimó que las disposiciones del Código Penal de Ecuador eran incompatibles con los artículos 1.1 y 7.5 de la CADH. Por ende, se había violado el artículo 2 de la Convención. Aunque en este caso, la Corte Interamericana no negó la validez jurídica de la ley, el Estado ecuatoriano declaró inconstitucional el artículo en cuestión de su Código Penal².

Además, hubo Estados que declararon la inconstitucionalidad de una ley, o impulsaron reformas legales, sin que la Corte Interamericana estableciera que fue una violación al artículo 2 de la $\mathrm{CADH}$.

En igual sentido se pronunciaron otros casos como: 19 comerciantes vs. Colombia (párr. 262); Huilca Tecse vs. Perú (párr. 108); Comunidad Moiwana vs. Surinam (párr.167); Masacre de Mapiripán vs. Colombia (párr. 304); Gómez

2 Al respecto el Estado de Ecuador declaró la inconstitucionalidad por razones de fondo y suspendió los efectos del último párrafo de este artículo, que dice: "Se excluye de estas disposiciones a los que estuvieren encausados, por delitos sancionados por la Ley sobre Sustancias Estupefacientes y Psicotrópicas". Dado por resolución del Tribunal Constitucional119, publicado en Registro Oficial, suplemento 222 de 24 de diciembre de 1997. Cfr. García-Sayán(2005).
Palomino vs. Perú (párr. 140); Blanco Romero vs. Venezuela (párr. 98); Baldeón García vs. Perú (párr. 201); Masacres de Ituango vs. Colombia (párr. 402); Masacre de Pueblo Bello vs. Colombia (párrs. 267-269); La Cantuta vs. Perú (párrs. 225-227) y Masacre de la Rochela vs. Colombia (párrs. 292-294).

En este marco, los tribunales constitucionales de Bolivia, Colombia y Perú, la Corte Suprema de Justicia de la Nación (Argentina), la Suprema Corte de Justicia de la Nación (México), la Suprema Corte de Justicia de la República Dominicana, y algunos tribunales superiores de Chile, han dado una clara señal de que sus ordenamientos internos están implementando las garantías internacionales de protección de derechos humanos (véase García-Sayán, 2008b).

Por ende, es más recurrente que los tribunales nacionales de los Estados del continente americano, requieran, cada vez más, de las argumentaciones de la Corte para la interpretación de la $\mathrm{CADH}$, que va a generar una homogeneización de las normas sobre derechos humanos.

Dicho todo esto, y a fin de dar solución a las cuestiones planteadas sobre la prevalencia de los tratados internacionales, en general se toma en cuenta la doctrina, la jurisprudencia de la Corte Interamericana o la práctica establecida.

En este sentido, las constituciones latinoamericanas conceden a los tratados internacionales, en materia de derechos humanos, el carácter: (i) supraconstitucional, (ii) constitucional, (iii) supralegal o (iv) legal.

\section{El carácter supraconstitucional del tratado internacional}

Significa que el tratado internacional tiene un estatus jurídico privilegiado. Se configura sobre cualquier norma del derecho interno e, incluso, sobre la propia Constitución nacional. Los mismos textos constitucionales son los que disponen tal solución e, indirectamente, pueden reformarla, siempre y cuando sean aprobados, cumpliendo ciertos requisitos previos establecidos. 
El antecedente tradicional en este mecanismo es el artículo 63 de la Constitución holandesa (Grondwet) de 1953, que disponía que un tratado puede apartarse de los términos constitucionales, siempre que el poder legislativo lo apruebe, de forma expresa y con una mayoría cualificada de los dos tercios de los votos.

Así, la doctrina entendía que la superioridad del tratado internacional sobre las "normas legales vigentes" del derecho interno, "incluía la Supremacía del tratado sobre la Constitución, y que al no estar facultados los jueces para realizar un control constitucional reparador, estos podían en la práctica hacer prevalecer el tratado por sobre el derecho interno" (Riofrío, 2007, p. 260) ${ }^{3}$.

Luego, con la reforma de la Constitución en 1983 la disposición cambió, señalando que

(...) toda provisión de un tratado opuesta a la Constitución debe ser aprobada por las cámaras con una mayoría, de, al menos, dos tercios de los votos, y que las regulaciones legales internas en vigor no son aplicables si entran en colisión con las de un tratado [Const.] Art. 84. Febrero 17 de 1983 (Holanda).

Ahora bien, la opción de la preeminencia del tratado de derechos humanos sobre la Constitución, es una aplicación de la doctrina "monista". Según Hans Kelsen, "la razón de la validez del orden jurídico nacional, se encuentra determinada por el derecho internacional" (1995, p. 436).

Es necesario anotar que, algunas veces, la primacía del tratado internacional respecto a la Constitución, se logra no por una norma expresa que lo indique, sino más bien por decisión de sus operadores jurídicos.

Sagüés (2005), pone de ejemplo el caso de la Corte Suprema de Justicia de la Nación Argentina, caso Ekmekdjian vs. Sofovich: acción de amparo que se discutía la operatividad, dentro del

3 Cfr. Massa(2011). derecho nacional de Argentina, sobre el derecho de réplica establecido en la $\mathrm{CADH}$ vigente, en ese país (ley 23.054).

La Corte Interamericana consideró, en virtud del Convenio de Viena-sobre el derecho de los tratados y aprobado por Argentina (ley 19.865)y a razón de los principios pacta sunt servanda y de la bona fide, que el Estado de Argentina estaba obligado a cumplir cabalmente con los tratados internacionales del que formaba parte, los hubiera suscrito, aprobado y ratificado; es decir, únicamente, podía no cumplir en caso de que se concurrieran supuestos raros, fijados en los artículos 27 y 46 de la Convención de Viena. En concreto, la conclusión de la Corte impuso, a los órganos del Estado de ese país, "asignar primacía al tratado ante un eventual conflicto con cualquier norma interna contraria" (Sagüés, 2005), y de esa "cualquier norma interna contraria", no exceptuó a la Constitución Argentina (Sagüés, 2005).

Por ello, los efectos de la supremacía de los tratados internacionales son dos: primero, el de la invalidez, es decir, en caso de conflicto entre la Constitución y el tratado internacional, prima el tratado. El conflicto puede ser, a su vez, normativo (la regla jurídica del tratado choca con la regla jurídica de la Constitución); o ideológico (base filosófica-política). En cualquiera de estas variables debe prevalecer el tratado, de manera que la cláusula constitucional contraria al tratado internacional se invalidará. Y segundo, de la armonización, que significa que las normas constitucionales deben de interpretarse de acuerdo con el tratado (artículos e ideología).

Al respecto, Sagüés (2005) refiere que mediante la interpretación "armonizante" de la Constitución, en relación con el tratado, puede "rescatarse" muchas normas constitucionales, con el fin de evitar la declaración de su invalidez y, en cambio, hacerlas útiles y conformes con el instrumento internacional (véase Henderson, 2005) A modo de ejemplo, se puede citar el caso de la Constitución Política de Colombia de 1991. 
En definitiva, las constituciones latinoamericanas que estiman que los tratados internacionales prevalecen sobre las leyes nacionales, son: la Constitución Política de la República de Guatemala del 31 de mayo de 1985; la Constitución Política de Colombia del 7 de julio de $1991^{4}$ y la Constitución de la República de Honduras del 11 de enero de 1982, que inspirada en la Constitución peruana de 1979, dedica todo el capítulo III a los tratados internacionales.

Particularmente, la Constitución de Guatemala en el artículo 46 declara: "Preeminencia del Derecho Internacional. Se establece el principio general de que en materia de derechos humanos, los tratados y convenciones aceptados y ratificados por Guatemala, tienen preeminencia sobre el derecho interno". Y la Constitución de Colombia en el artículo 93 dice:

Los tratados y convenios internacionales ratificados por el Congreso, que reconocen los derechos humanos y que prohíben su limitación en los Estados de excepción, prevalecen en el orden interno.

Los derechos y deberes consagrados en esta Carta, se interpretarán de conformidad con los tratados internacionales sobre derechos humanos ratificados por Colombia [...].

Por su parte, la Constitución de Honduras en los artículos 16, 17 y 18 refiere:

16. Todos los tratados internacionales deben ser aprobados por el Congreso Nacional antes de su ratificación por el poder ejecutivo.

Los tratados internacionales celebrados por Honduras con otros Estados, una vez que entran en vigor, forman parte del derecho interno.

4 Constitución que sufrió diferentes reformas en 1993, 1995, 1996, 1997, 1999, 2000, 2001, 2002, 2003, 2004 y su última actualización, por el decreto 2576 del 27 de julio de 2005.
17. Cuando un tratado internacional afecte una disposición constitucional, debe ser aprobado por el mismo procedimiento que rige la reforma de la Constitución antes de ser ratificado por el poder ejecutivo.

18. En caso de conflicto entre el tratado o convención la ley prevalecerá el primero.

\section{El carácter constitucional del tratado internacional}

Las constituciones nacionales llevan a los tratados internacionales a la misma jerarquía normativa de la Constitución, siendo el valor máximo que se concede dentro de un ordenamiento jurídico. Por lo tanto, los tratados adquieren la superioridad y el rigor propio de la Constitución y, además, van a gozar de esa característica inherente de la norma constitucional, al ser regla jurídica vinculante para el poder público y privado. No obstante, técnicamente el tratado no forma parte de la Constitución, pero sí va a valer como el texto constitucional.

A la fecha, en el derecho constitucional latinoamericano, se ha convertido en una tendencia muy fuerte el reconocimiento expreso en sus textos constitucionales, del carácter constitucional de los tratados de derechos humanos. En este supuesto, nos encontramos ante tres posibles situaciones.

Primera, se hace mención expresa. Es el caso de la Constitución de la República Bolivariana de Venezuela del 30 de diciembre de 1999 y de la Constitución de la Nación Argentina del 22 de agosto de $1994^{5}$. La Constitución venezolana en su artículo 23 expresa:

Los tratados, pactos y convenciones relativos a derechos humanos, suscritos y ratificados por Venezuela, tienen jerarquía constitucional y prevalecen en el orden interno, en la medida en que contengan normas sobre su

5 Para un estudio detallado sobre el caso argentino véase Bidart (2006). 
goce y ejercicio más favorables a las establecidas por esta Constitución y la ley de la República, y son de aplicación inmediata y directa por los tribunales y demás órganos del poder público.

Y la Constitución de Argentina en su artículo 75.22 reza:

Aprobar o desechar tratados concluidos con las demás naciones y con las organizaciones internacionales y los concordatos con la Santa Sede. Los tratados y concordatos tienen jerarquía superior a las leyes.

La Declaración Americana de los Derechos y Deberes del Hombre; la Declaración Universal de Derechos Humanos; la Convención Americana sobre Derechos Humanos [...]; en las condiciones de su vigencia, tienen jerarquía constitucional, no derogan artículo alguno de la primera parte de esta Constitución y deben entenderse complementarios de los derechos y garantías por ella reconocidos (...).

Segunda, no hay mención expresa, pero implícitamente sí existe la evocación al concepto. Así, se les reconoce a los individuos, "la plena vigencia de los derechos consignados", como la Constitución Política de la República de Nicaragua de 9 de enero de 1987en su artículo 46:

En el territorio nacional toda persona goza de la protección estatal y del reconocimiento de los derechos inherentes a la persona humana, del irrestricto respeto, promoción y protección de los derechos humanos, y de la plena vigencia de los derechos consignados en la Declaración Universal de los Derechos Humanos; en la Declaración Americana de Derechos y Deberes del Hombre, en el Pacto Internacional de Derechos Económicos, Sociales y Culturales, en el Pacto Internacional de Derechos Civiles y Políticos de la Organización de las Naciones Unidas y en la Convención Americana de Derechos Humanos de la Organización de Estados Americanos.
Y tercera, no está implícito ni expreso en la Constitución. Se opta por una asimilación genérica de los tratados o convenios internacionales al texto constitucional. Era el caso del artículo 105 de la derogada Constitución peruana de 1979, por la actual Constitución Política de 1993, que declara: "Los preceptos contenidos en los tratados relativos a derechos humanos, tienen jerarquía constitucional. No pueden ser modificados sino por el procedimiento que rige para la reforma de la Constitución”.

No obstante, fuera de estos tres supuestos, quedan excluidos aquellos que, por vía de interpretación, puede considerarse que otorgan tal carácter (Dulitzky, 1997).

\section{El carácter supralegal del tratado internacional}

Se conoce también como "subconstitucional de primer grado" (Henderson, 2005, pp. 278279). Según esta postura, el valor del tratado internacional, sea de cualquier índole, está por debajo de la Constitución, aunque prima sobre la ley ordinaria.

Por ello, los tratados internacionales deben subordinarse y estar en concordancia, ya no solo con el contenido, sino también deben tener en cuenta la forma y las reglas en su incorporación al derecho interno y a la Constitución nacional, respectivamente. Hay que tomar en consideración que los tratados internacionales pueden colisionar con la Constitución y se puede interponer una acción de inconstitucionalidad; en cambio, si esta colisión se produce con una ley, el tratado prima sobre las normas internas.

En este escenario los efectos pueden ser múltiples. Así, se puede invalidar un tratado contrario a la Constitución. Esta situación puede darse, pese a que, cuando se ratificó el tratado internacional, este era perfectamente compatible con la Constitución, pero con posterioridad ya no lo es, a causa de una reforma constitucional contraria al tratado. 
Además, los tratados internacionales de derechos humanos pueden interpretarse, en armonía con las regulaciones constitucionales, a favor de la Constitución. En este caso, como señala Sagüés (2005), no respeta los principios pacta sunt servanda ni de la bona fide, que autoriza evasiones al cumplimiento del tratado, con el pretexto de la supremacía constitucional. De igual modo, el tratado prevalece sobre una ley ordinaria. En consecuencia, la ley no puede derogarla, aunque fuera posterior al tratado.

Por último, las leyes nacionales se interpretan conforme a los tratados internacionales de derechos humanos (interpretación armonizante, a favor del tratado).

En concreto, en este rubro supralegal, se incluyen: la Constitución Política de la República de Costa Rica del 7 de noviembre de 1949 que ha sido reformada 28 veces desde entonces (su última modificación fue con la ley 8365 del 15 de julio del 2003); la Constitución de la República de El Salvador del 15 de diciembre de 1983; la Constitución de la República de Paraguay del 20 de junio de 1992; la Constitución de la República Federativa de Brasil del 5 de octubre de 1988; y la novísima Constitución de la República de Ecuador del 20 de octubre de 2008.

La Constitución de Costa Rica en su artículo 7 señala que:

Los tratados públicos, los convenios internacionales y los concordatos, debidamente aprobados por la Asamblea Legislativa, tendrán desde su promulgación o desde el día que ellos designen, autoridad superior a las leyes.

Los tratados públicos y los convenios internacionales referentes a la integridad territorial o la organización política del país, requerirán

$6 \quad$ No obstante la clasificación realizada del valor supralegal de los tratados internacionales, es importante destacar que el profesor Antônio Augusto Cançado (1996) considera que la Constitución es de naturaleza constitucional. de la aprobación de la Asamblea Legislativa, por votación no menor de las tres cuartas partes de la totalidad de sus miembros, $y$ la de los dos tercios de los miembros de una Asamblea Constituyente, convocada al efecto(artículo reformado por ley 4123 de 31 de mayo de 1968).

La Constitución de El Salvador en su artículo 144 afirma:

Los tratados internacionales celebrados por El Salvador con otros Estados o con organismos internacionales, constituyen leyes de la República al entrar en vigencia, conforme a las disposiciones del mismo tratado y de esta Constitución.

La ley no podrá modificar o derogar lo acordado en un tratado vigente para El Salvador. En caso de conflicto entre el tratado y la ley, prevalecerá el tratado.

La Constitución de Paraguay en sus artículos 137 y 141 asevera:

137. De la supremacía de la Constitución. La ley suprema de la República es la Constitución. Esta, los tratados, convenios y acuerdos internacionales aprobados y ratificados, las leyes dictadas por el Congreso y otras disposiciones jurídicas de inferior jerarquía, sancionadas en consecuencia, integran el derecho positivo nacional en el orden de prelación enunciado.

Quienquiera que intente cambiar dicho orden, al margen de los procedimientos previstos en esta Constitución, incurrirá en los delitos que se tipificarán y penarán en la ley.

141. De los tratados internacionales. Los tratados internacionales válidamente celebrados, aprobados por ley del Congreso, y cuyos instrumentos de ratificación fueran canjeados o depositados, forman parte del ordenamiento legal interno con la jerarquía que determina el artículo 137. 
La Constitución de Brasil en sus artículos 4 y 5.2 manifiesta: "4. A República Federativa do Brasil rege-se nas suas relações internacionais pelos seguintes princípios: [...] II - prevalência dos direitos humanos"; $y$ "5.2. Os direitos e garantias expressos nesta Constituição não excluem outros decorrentes do regime e dos princípios por ela adotados, ou dos tratados internacionais em que a República Federativa do Brasil seja parte”.

Y por último, la Constitución de Ecuador en su artículo 417 proclama:

Los tratados internacionales ratificados por el Ecuador se sujetarán a lo establecido en la Constitución. En el caso de los tratados y otros instrumentos internacionales de derechos humanos se aplicarán los principios pro ser humano, de no restricción de derechos, de aplicabilidad directa y de cláusula abierta establecidos en la Constitución.

\section{El carácter legal del tratado internacional}

En este supuesto, sin duda, el valor del tratado está por debajo de la Constitución. Así mismo, no hay razón para dar preferencia al tratado sobre una ley, salvo que la Constitución así lo determine.

El argumento de esta postura es complejo, porque parte de la premisa de que el orden jurídico nacional y el internacional son intrínsecamente diferentes e independientes (es la postura dualista). Por ello, el tratado tendrá validez en el ámbito internacional, pero, dentro del ámbito nacional del Estado, será la Constitución la que condicione al Estado.

En definitiva, el tratado internacional tiene la misma cotización jurídica que una ley. Por lo tanto, sus efectos serán: primero, si el tratado entra en colisión con la Constitución, será inconstitucional, y se interpretará desde las pautas de la Constitución. Segundo, el tratado, aprobado por una ley, deroga a una ley anterior que se le oponga (lex posteriori derogat priori). Tercero, una ley ulterior puede modificar al tratado. Cuarto, el tratado deberá funcionar, aunque sea en última instancia, según la ideología jurídica imperante en el derecho nacional, dada su "conversión" de derecho externo (internacional), a derecho interno (nacional).

Finalmente, en esta postura no se satisface los postulados de pacta sunt servanda ni de la bona fide, dando posibilidad, más que en ninguna otra tesis, a evasiones nacionales respecto al cumplimiento del tratado.

En este rubro tenemos a la Constitución Política de los Estados Unidos Mexicanos del 5 de febrero de 1917; y a la Constitución de la República Oriental del Uruguay del 27 de noviembre de 1967.

Por un lado, la Constitución de México-que a diferencia de la mayoría de los países latinoamericanos no ha cambiado por una nueva-ha sido reformada únicamente para ajustarse a los cambios de los tiempos y a las condiciones políticas del país. Desde su publicación hasta la fecha ha sufrido 532 reformas $^{7}$. La última se efectuó en el capítulo I: De los derechos humanos y sus garantías, en el $2011^{8}$.

Por ende, la actual Constitución mexicana es una aportación de la tradición jurídica mexicana al constitucionalismo universal, dado que fue la primera Constitución de la historia en incluir los derechos sociales, dos años antes que la Constitución de Weimar de 1919. Así:

En los Estados Unidos Mexicanos todas las personas gozarán de los derechos humanos reconocidos en esta Constitución y en los tratados internacionales de los que el Es-

$7 \quad$ El artículo 135 de la Constitución permite reformar y adicionar el contenido de la misma. Para modificarla se requiere que el Congreso de la Unión, por el voto de las dos terceras partes de los individuos presentes, acuerde las reformas o adiciones, y que estas sean aprobadas por la mayoría de las legislaturas de los Estados.

8 Modificada la denominación por decreto publicado en el Diario Oficial de la Federación el 10 de junio de 2011. 
tado mexicano sea parte, así como de las garantías para su protección, cuyo ejercicio no podrá restringirse ni suspenderse, salvo en los casos y bajo las condiciones que esta Constitución establece (reformado mediante decreto publicado en el Diario Oficial de la Federación el 10 de junio del 2011).

Las normas relativas a los derechos humanos se interpretarán de conformidad con esta Constitución y con los tratados internacionales de la materia favoreciendo en todo tiempo a las personas la protección más amplia (adicionado mediante decreto publicado en el Diario Oficial de la Federación el 10 de junio del 2011).

Todas las autoridades, en el ámbito de sus competencias, tienen la obligación de promover, respetar, proteger y garantizar los derechos humanos de conformidad con los principios de universalidad, interdependencia, indivisibilidad y progresividad.

En consecuencia, el Estado deberá prevenir, investigar, sancionar y reparar las violaciones a los derechos humanos, en los términos que establezca la ley[...] (adicionado mediante decreto publicado en el Diario Oficial de la Federación el 10 de junio del 2011) (artículo 1).

Ahora bien, en cuanto a la primacía de tratados, la Constitución mexicana en el artículo 133 expresa:

Esta Constitución, las leyes del Congreso de la Unión que emanen de ella y todos los tratados que estén de acuerdo con la misma, celebrados y que se celebren por el presidente de la República, con aprobación del Senado, serán la ley suprema de toda la Unión. Los jueces de cada estado se arreglarán a dicha Constitución, leyes y tratados, a pesar de las disposiciones en contrario que pueda haber en las constituciones o leyes de los estados(artículo reformado mediante decreto publicado en el Diario Oficial de la Federación el 18 de enero de 1934).

Y por otro lado, respecto al texto de la vigente Constitución de Uruguay, es básicamente el de
1967, el cual a su vez tuvo varias enmiendas posteriores ${ }^{9}$; como se entiende que la reforma de 1996 fue muy importante por modificar los ciclos electorales, por sencillez, se habla de la Constitución de 1997. En cuanto a la primacía de tratados, la Constitución de Uruguay en su artículo 6 manifiesta: "En los tratados internacionales que celebre la República propondrá que la cláusula de que todas las diferencias que surjan entre las partes contratantes, serán decididas por el arbitraje u otros medios pacíficos".

Una vez descrito el panorama, el futuro de los cuatro postulados expuestos no es previsible. En palabras de Sagüés (2005), muy probablemente sea la doctrina de la supraconstitucionalización la que tenga más posibilidades de continuar en el tiempo, a fin de sostener la primacía del bien común internacional sobre el bien común nacional, aunque tenga serios obstáculos y resistencia de los Estados, influidos por la doctrina de la soberanía.

Sin embargo, es la tesis de la constitucionalización la que más se desarrolla en la actualidad.

La tesis supralegal, en términos de Sagüés (2005), es quizá a la fecha, lo menos que puede brindar un constituyente actualizado. En comparación a "cinco décadas atrás, este paso importa, no obstante, un significativo avance jurídico, en aras de tutelar los derechos humanos de fuente internacional" (Sagüés, 2005, p. 103).

Por último, la tesis legal hoy en día prácticamente no se acepta, por la deslegitimación axiológica que ha sufrido y porque esto implica autorizar directamente múltiples evasiones al cumplimiento de los compromisos internacionales contraídos por un Estado (Sagüés, 2005).

En general, este carácter que le otorga la Constitución a los tratados internacionales sobre derechos humanos, por sí solo, no constituye

$9 \quad$ Primera, del 26 de noviembre de 1989; segunda, del 26 de noviembre de 1994 y del 8 de diciembre de 1996; y tercera, del 31 de octubre de 2004. 
una garantía de una efectiva protección de los derechos humanos. En la praxis, dista mucho la pretensión de la realidad, ya que muchos de los Estados latinoamericanos no cumplen lo estipulado en sus constituciones (son nominales), y se quedan en meras buenas intenciones, frente a lo que realmente hacen.

Cumplir con estas obligaciones jurídicas no es una tarea fácil para el poder jurisdiccional del continente latinoamericano. Este hecho se debe, "en parte, por una difundida cultura de oportunismo jurídico: las normas se cumplen si resulta conveniente; de lo contrario, no pasan de ser un lineamiento de aplicación flexible" (Steiner \& Leyers, 2010, p. 96).

Infortunadamente, todavía se dan muchos casos en que los derechos humanos siguen siendo considerados como simples enunciados declarativos y no como derechos reales o efectivos de las personas, que deben ser protegidos con la intervención del Estado. Por ello, en esta línea, Sergio García (2008) indica que los derechos humanos incluso se juzgan como obstáculo o riesgo para la seguridad pública o nacional.

Superar este problema es posible. Se encuentra en manos de los propios Estados, en especial, si se lo proponen los poderes estatales, por lo general, del legislativo, ejecutivo y judicial.

Por ello, el legislador debe armonizar el derecho interno con los esquemas internacionales, además de salvaguardar esa correspondencia. En palabras de García-Sayán, "la opción de adecuar no solo las normas jurídicas, sino también el funcionamiento del aparato de Estado, en su conjunto, a la norma internacional" (2008a, p. 13) ${ }^{10}$.

En cuanto al poder ejecutivo, debe desenvolverse dentro del contexto adecuado, cuando surjan

10 Cfr. Corte Interamericana de Derechos Humanos. caso Velásquez Rodríguez vs. Honduras; sentencia de fondo de 29 de julio de 1988, párrs. 164-169, 173-174. Cfr. artículo 2.2 del Pacto Internacional de Derechos Civiles y Políticos. diferencias entre las normas del ordenamiento interno, la Constitución y el derecho internacional. En cualquier caso, la justicia debe velar por su cumplimiento o la conciliación (Steiner \& Leyers, 2010) (véase Almirón, 2009; García, 2008 \& García-Sayán, 2005).

Empero, debemos tener en cuenta que esta tarea no solo depende de los gobernantes de los Estados, sino también de los tribunales nacionales, que tienen un rol importante, ya que el espacio institucional sirve a la ciudadanía como principal y fundamental referente para la protección de los derechos (García-Sayán, 2010).

Como resultado, los propios ciudadanos son los vehículos principales para que el Estado pueda incorporar activamente, en su ordenamiento interno, las pautas contenidas en los tratados internacionales sobre derechos humanos, ya sea de manera individual u organizados en forma de asociaciones, organizaciones no gubernamentales, fundaciones, federaciones o representados por abogados, implicados con la causa.

Es esencial el papel de los jueces y los abogados para poder asegurar la implementación interna de las pautas y normas internacionales sobre derechos humanos, y también de la jurisprudencia supranacional. Es decir, que mientras no se demande, desde la propia sociedad, la protección real de los derechos humanos, el Estado tampoco le pondrá mucho interés.

En lo que respecta a los actores nacionales, hacemos alusión especial a las cortes o tribunales constitucionales. Por su parte, las cortes o tribunales supremos, en la emisión de su respectiva jurisprudencia, son los que van a recoger estos impulsos de la Corte Interamericana (García-Sayán, 2008b); aunque hasta ahora no lo han realizado con la adecuada coherencia metodológica.

El artículo 2 de la CADH pretende armonizar el derecho nacional con las normas de la $\mathrm{CADH}$, en la medida en que las constituciones nacionales, que aún no han recogido las normas respectivas, 
puedan deducir directamente de la Convención. Por ello, el establecimiento del derecho constitucional o convencional, en el derecho ordinario o nacional, es necesario para una protección eficaz de los derechos humanos (García-Sayán, 2008b; Steiner \& Leyers, 2010).

\section{CONCLUSIONES}

- En América Latina, el grado de protección de los derechos humanos que los Estados asumen frente a sus ciudadanos no es tan alentador. Por lo que los tratados internacionales de derechos humanos, se han constituido en los mejores instrumentos, a través de los cuales los Estados adquieren compromisos internacionales con otros Estados $\mathrm{u}$ organismos internacionales, a fin de lograr su inserción al mundo globalizado y una mejor protección de los derechos humanos de sus ciudadanos. Además, se instituyen como una garantía para limitar el poder de los Estados frente al individuo.

- Es indispensable que los tratados internacionales de derechos humanos sean considerados como un instrumento conceptual y operacional, de las personas que están inmersas en este proceso dentro de la función pública (poder legislativo, ejecutivo y judicial), especialmente en toda la administración de justicia de los Estados, tanto los jueces del poder judicial, como el conjunto de los integrantes y miembros de los tribunales nacionales.

- Las constituciones de los Estados latinoamericanos necesitan, en primer lugar, contar con una cláusula constitucional sobre la primacía del tratado de derechos humanos; $y$, en segundo lugar, es preciso que las constituciones dejen claro el carácter que posee el tratado internacional frente a su legislación jurídica (supraconstitucional, constitucional, supralegal o legal), por cuanto la inexistencia o la imprecisión de la cláusula constitucional puede generar conflictos en la aplicación de un tratado frente a la legislación interna, y avivar aún más el problema constitucional de la primacía de los tratados.

- En la actualidad, a los Estados todavía les queda mucho trabajo pendiente sobre este tema para que el proceso de nacionalización de las pautas internacionales, se lleve a cabo sin generar conflictos jurídicos en el derecho interno. Pero también pasa por superar la falta de compromiso político estatal, frente a los instrumentos internacionales de derechos humanos.

No obstante, de cara a la realidad, confiamos en que, en un futuro no tan lejano, estas barreras formen parte del propio proceso de evolución jurídico-político de los Estados, lo que repercutirá positivamente en beneficio de las personas de Latinoamérica.

\section{REFERENCIAS}

Albanese, S. (2008). La internacionalización del derecho constitucional y la constitucionalización del derecho internacional. En AAVV. El control de convencionalidad (pp. 13-45). Buenos Aires: Ediar Editores S. A.

Almirón, E. (2009). Derechos fundamentales y su incidencia en el plexo constitucional de los Estados. En G. Elsner (ed.). Anuario del derecho constitucional latinoamericano (pp. 525-539). Montevideo: Konrad-Adenauer-Stiftung.

Álvarez, J. (2001). Tratados internacionales y ley interna. Lima: Fondo Editorial de Cultura.

Bidart, G. J. (2006). Tratado elemental de derecho constitucional argentino. Tomo III. El derecho internacional de los derechos humanos y la reforma constitucional de 1994 (reimpresión). Buenos Aires: Ediar Editores S.A.

Bobbio, N. (1982). Presente y futuro de los derechos del hombre, El problema de la guerra y las vías de la paz. Barcelona: Gedisa.

Cançado, A. (1996). Direito internacional e direito interno: sua interação naproteção dos 
direitos humanos. Recuperado de http://www. pge.sp.gov.br/centrodeestudos/bibliotecavirtual/ instrumentos/introd.htm

Constitución de Holanda. (1983). Febrero 17.

Constitución de la Nación Argentina. (1994). Agosto 22.

Constitución de la República Bolivariana de Venezuela. (1999). Diciembre 30.

Constitución de la República de Ecuador. (2008). Octubre 20.

Constitución de la República de El Salvador. (1983). Diciembre 15.

Constitución de la República de Honduras. (1982). Enero 11.

Constitución de la República de Paraguay. (1992). Junio 20.

Constitución de la República Federativa de Brasil. (1988). Octubre 5.

Constitución de la República Oriental del Uruguay. (1967). Noviembre 27.

Constitución Política de Colombia. (1991). Julio 7.

Constitución Política de la República de Costa Rica. (1949). Noviembre 7.

Constitución Política de la República de Guatemala. (1985). Mayo 31.

Constitución Política de la República de Nicaragua. (1987). Enero 9.

Constitución Política de los Estados Unidos Mexicanos. (1917). Febrero 5.

Constitución Política del Perú. (1979). Julio 12.

Constitución Política del Perú.(1993). Diciembre 29.

Convención Americana sobre Derechos Humanos (Pacto de San José). (1969). Noviembre 22.

Corte Interamericana de Derechos Humanos.
(1988). Caso Velásquez Rodríguez vs. Honduras. Sentencia de fondo, de 29 de julio. Serie C 4.

Corte Interamericana de Derechos Humanos. (1997). Caso Suárez Rosero vs. Ecuador. Sentencia de fondo, de 12 de noviembre. Serie C 35.

Corte Interamericana de Derechos Humanos. (1998). Caso Paniagua Morales y otros vs. Guatemala. Sentencia de fondo, de 8 de marzo. Serie C 37.

Corte Interamericana de Derechos Humanos. (1998). Caso Castillo Páez vs. Perú. Sentencia de reparaciones y costas, de 27 de noviembre. Serie C 43.

Corte Interamericana de Derechos Humanos. (1999). Caso Castillo Petruzzi vs. Perú. Sentencia de fondo, reparaciones y costas, de 30 de mayo. Serie C 52.

Corte Interamericana de Derechos Humanos. (1999). Caso de los "Niños de la Calle" (Villagrán Morales y otros) vs. Guatemala. Sentencia de fondo, de 19 de noviembre. Serie C 63.

Corte Interamericana de Derechos Humanos. (2009). Caso González y otras ("Campo Algodonero") vs. México. Sentencia de excepción preliminar, fondo, reparaciones y costas, de 16 de noviembre. Serie C 205.

Corte Interamericana de Derechos Humanos. (2000). Caso Bámaca Velásquez vs. Guatemala. Sentencia de fondo, de 25 de noviembre. Serie C 70 .

Corte Interamericana de Derechos Humanos. (2001). Caso Barrios Altos vs. Perú. Sentencia de fondo, de 14 de marzo. Serie C 75.

Corte Interamericana de Derechos Humanos. (2001). Caso Barrios Altos vs. Perú. Sentencia de interpretación de fondo, de 3 de septiembre. Serie C 83.

Corte Interamericana de Derechos Humanos. (2003). Caso Bulacio vs. Argentina. Sentencia de fondo, reparaciones y costas, de $18 \mathrm{de}$ septiembre. Serie C 100. 
Corte Interamericana de Derechos Humanos. (2004). Caso 19 comerciantes vs. Colombia. Sentencia de fondo, reparaciones y costas, de 5 de julio. Serie C 109.

Corte Interamericana de Derechos Humanos. (2005). Caso Blanco Romero y otros vs. Venezuela. Sentencia de fondo, reparaciones y costas, de 28 de noviembre. Serie C 138.

Corte Interamericana de Derechos Humanos. (2005). Caso Gómez Palomino vs. Perú. Sentencia de fondo, reparaciones y costas, de 22 de noviembre. Serie C 136.

Corte Interamericana de Derechos Humanos. (2005). Caso de la Masacre de Mapiripán vs. Colombia. Sentencia de fondo, reparaciones y costas, de 15 de septiembre. Serie C 134.

Corte Interamericana de Derechos Humanos. (2005). Caso de la Comunidad Moiwana vs. Surinam. Sentencia de excepciones preliminares, fondo, reparaciones y costas, de 15 de junio. Serie C 124.

Corte Interamericana de Derechos Humanos. (2005). Caso Huilca Tecse vs. Perú. Sentencia de fondo, reparaciones y costas, de 3 de marzo. Serie C 121.

Corte Interamericana de Derechos Humanos. (2006). Caso La Cantuta vs. Perú. Sentencia de fondo, reparaciones y costas, de 29 de noviembre. Serie C 162.

Corte Interamericana de Derechos Humanos. (2006). Caso Almonacid Arellano vs. Chile. Sentencia de excepciones preliminares, fondo, reparaciones y costas, de 26 de septiembre. Serie C 154.

Corte Interamericana de Derechos Humanos. (2006). Caso Claude Reyes y otros vs. Chile. Sentencia de fondo, reparaciones y costas, de 19 de septiembre. Serie C 151.

Corte Interamericana de Derechos Humanos. (2006). Caso de las Masacres de Ituango vs. Colombia. Sentencia de excepción preliminar, fondo, reparaciones y costas, de 1 de julio. Serie C 148.
Corte Interamericana de Derechos Humanos. (2006). Caso Baldeón García vs. Perú. Sentencia de fondo, reparaciones y costas, de 6 de abril. Serie C 147.

Corte Interamericana de Derechos Humanos. (2006). Caso de la Masacre de Pueblo Bello vs. Colombia. Sentencia de fondo, reparaciones y costas, de 31 de enero. Serie C 140.

Corte Interamericana de Derechos Humanos. (2007). Caso de la Masacre de la Rochela vs. Colombia. Sentencia de fondo, reparaciones y costas, de 11 de mayo. Serie C 163.

Corte Interamericana de Derechos Humanos. (2012). Caso Atala Riffo y niñas vs. Chile. Sentencia de fondo, reparaciones y costas, de 24 de febrero. Serie C 239.

Declaración Americana de los Derechos y Deberes del Hombre. (1948). Aprobada en la IX Conferencia Internacional Americana (marzo-mayo).

Declaración Universal de Derechos Humanos. (1948). Diciembre 10.

Dulitzky, A. (1997). La aplicación de los tratados sobre derechos humanos por los tribunales locales: un estudio comparado. En AA.VV. La aplicación de los tratados sobre derechos humanos por los tribunales locales (pp. 39-74).Buenos Aires: Centro de Estudios Legales y Sociales.

Durán, P. (1993). Manual de derechos humanos. Granada: Comares.

Eguiguren, F. J. (2004). "Presentación" a Ana Salado Osuna. Los casos peruanos ante la Corte Interamericana de Derechos Humanos. Trujillo: Editora Normas Legales S.A.C.

García, D. (2002). Amnistía y derechos humanos. A propósito de la sentencia de la Corte Interamericana de Derechos Humanos en el caso Barrios Altos. En: R. Méndez (coord.). Derecho internacional de los derechos humanos (pp. 117130). México D. F.: Instituto de Investigaciones Jurídicas, Memoria del VII Congreso Iberoamericano de Derecho Constitucional, Universidad Nacional Autónoma de México. 
García, S. (2008). Recepción de la jurisprudencia interamericana sobre derechos humanos en el derecho interno. En G. Elsner (ed.). Anuario del derecho constitucional latinoamericano (pp. 353375). Montevideo: Konrad-Adenauer-Stiftung.

García-Sayán, D. (2003a). La recepción nacional del derecho internacional de los derechos humanos y de la jurisprudencia de la Corte Interamericana de Derechos Humanos. Recuperado de $h$ ttp://biblio.juridicas. unam. $m x /$ libros/6/2740/11.pdf

García-Sayán, D. (2003b). Los derechos humanos y la globalización, avances y retos. Lima: Comisión Andina de Juristas.

García-Sayán, D. (2005). Una viva interacción: Corte Interamericana y tribunales internos. En La Corte Interamericana de Derechos Humanos. Un cuarto de siglo: 1979-2004 (pp. 325-384). Recuperado de http://www.corteidh.or.cr/docs/ libros/cuarto\%20de\%20siglo.pdf

García-Sayán, D. (2008a). Sistema Interamericano de Derechos Humanos: efectos de las decisiones de la CIDH. Diálogo Político, XXV(4), diciembre, 11-35.

García-Sayán, D. (2008b). Justicia interamericana y tribunales nacionales. En G. Elser (ed.). Anuario de derecho constitucional latinoamericano (pp. 377-398). Montevideo: Konrad-AdenauerStiftung.

García-Sayán, D. (2010). "Prólogo" a Elizabeth Salmón Garate, Jurisprudencia de la Corte Interamericana de Derechos Humanos. Tomo 1. Lima: Instituto de Democracia y Derechos Humanos de la Pontificia Universidad Católica del Perú.

Gros, H. (1988). Estudios sobre derechos humanos II. Madrid: Instituto Interamericano de Derechos Humanos, Civitas S.A.

Henderson, H. (2005). Los tratados internacionales de derechos humanos en el orden interno: la importancia del principio pro homine. En Retos de la judicialización. En el proceso de verdad, justicia, reparación y reconciliación (pp. 272-289), Lima: Coordinadora Nacional de Derechos Humanos. Kelsen, H. (1995). Teoría general del derecho y del Estado. México D. F.: Universidad Nacional Autónoma de México.

Massa, G. (2011). Los sistemas constitucionales de Holanda y Luxemburgo. Revista de Derecho Constitucional Europeo (ReDCE), 8 (15), enero-junio, 185-222. Recuperado de http://www.ugr.es/ redce/ REDCE15/articulos/04GMGallerano.htm

Pontificia Universidad Católica del Perú. (2003). Documentos II. Evolución de las sentencias de la CIDH: escrutinio normativo. Agenda Internacional, IX(18), 315-317.

Riofrío, J. C. (2007). ¿Prevalecen los tratados internacionales sobre la Constitución? Propuesta de una doctrina no extremista. En: G. Elser (ed.). Anuario de derecho constitucional latinoamericano (pp. 259-281). Montevideo: KonradAdenauer-Stiftung.

Rodríguez, G. (2009). Derechos humanos: jurisprudencia internacional y jueces internos. Recuperado de http://biblio.juridicas.unam. $m x /$ libros/6/2740/19.pdf

Sagüés, N. P. (2005). Mecanismos de incorporación de los tratados internacionales sobre derechos humanos, al derecho interno. En Retos de la judicialización. En el proceso de verdad, justicia, reparación y reconciliación (pp. 94-103). Lima: Coordinadora Nacional de Derechos Humanos.

Salado, A. (2004). Los casos peruanos ante la Corte Interamericana de Derechos Humanos. Trujillo: Editora Normas Legales S.A.C.

Steiner, C. \& Leyers, S. (2010). La Corte IDH: impulsadora de una efectiva protección de los DDHH. Diálogo Político, XXVII(4), diciembre, 91-109. 